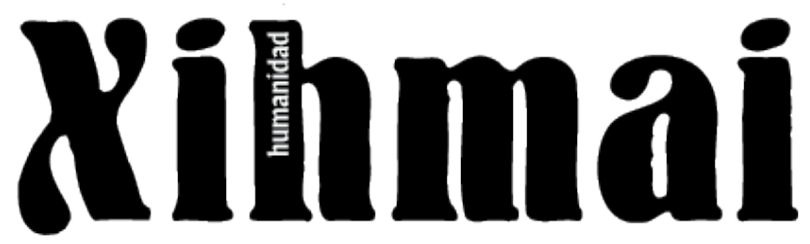 \\ Revista Xihmai \\ ISSN 1870-6703 \\ http://www.lasallep.edu.mx/revistas/index.php/xihmai/ \\ Universidad la Salle Pachuca \\ http://doi.org/10.37646/xihmai.v1i2.21
}

\section{CONCEPTO DE POLÍTICA Y VIDA COTIDIANA CONCEPT OF POLITICS AND EVERYDAY LIFE}

\author{
Esther Fragoso Fernández \\ Universidad la Salle Pachuca
}

Nota sobre el autor

Maestra en Educación Familiar por la Universidad Panamericana, Licenciada en Filosofía por la Universidad Nacional Autónoma de México. Docente-Investigadora de la Universidad La Salle Pachuca.

Esta investigación fue financiada con recursos del autor.

Remita cualquier duda sobre este artículo al siguiente correo electrónico: efragoso@lasallep.edu.mx

Recibido:1/1/2006

Aceptado:1/1/2006

Derechos de autor (C) 2006 Universidad La Salle Pachuca - Todos los derechos reservados.

Condiciones de Uso: La reproducción total o parcial de la obra en soporte electrónico queda prohibida sin la autorización de la Universidad la Salle Pachuca. 


\title{
CONCEPTO DE POLÍTICA Y VIDA COTIDIANA
}

\author{
Esther Fragoso Fernández ${ }^{*}$
}

\section{Resumen}

Es incorrecto pensar que la política nos es ajena, que por mas ideales que se tengan sólo compete a los que están en el gobierno y que la gente "común y corriente" no puede hacer nada para cambiar las cosas, de tal modo que solo hay que preocuparse por "lo propio", como si lo que sucediese en la política atañe solo a los políticos. Para aclarar esto, se busca a través de esta reflexión analizar diferentes significados y ámbitos de aquello a lo que se llama política, es una indagación del concepto de política y su interacción con otras actividades en las que el hombre se circunscribe, ubicada en el área de la filosofía política, ámbito de las ideologías como valoraciones de las ideas políticas y la reflexión de sus consecuencias en los grupos sociales.

\section{Abstract}

It is incorrect to think that the politics is to other people because his ideals only concern whose are in the government and that "ordinary" people cannot make anything to change the things, in this way it is necessary to worry about "the own" problems, as if what happens in the politics concerns only to the politicians. To clarify this, it is looked for through this reflection to analyze different meanings and environments from what calls politics, it is an inquiry of politics's concept and their interaction with other activities in that the man is bounded, located in the area of the political 
philosophy, environment of the ideologies like valuations of the political ideas and the reflection of his consequences in the social groups.

\section{DEFINICIONES DE POLITICA}

El termino política es polisémico por lo cual es necesario determinar el significado en cada uno de sus usos.

Etimológicamente la palabra política proviene "del latín politicus adjetivo de político; del griego polítikòs, de los ciudadanos; de politês ciudadano; y de pòlis ciudad" (GÓMEZ, 2001 p 552), es decir, politica es aquello que involucra a los ciudadanos y los asuntos públicos.

Por otra parte, la definición nominal se entiende como "gobierno, guía, dirección, mandato" (LAROUSSE, 2001 p 413)

En contraste, la definición negativa se refiere a lo que no es privado

La definición genética, que se refiere al origen, puede ubicarse en "la obra de Aristóteles intitulada Política, que es considerada el primer tratado sobre la naturaleza, las funciones y las divisiones del Estado, y sobre las varias formas de gobierno" (BOBBIO, 1995 p 1209)

La definición lexicológica remite al arte, doctrina u opinión referente al gobierno de los Estados; actividad de los que rigen o aspiran a regir los asuntos públicos; acción del ciudadano cuando interviene en los asuntos públicos con su opinión, con su voto, o de cualquier otro modo; cortesía 
y buen modo de portarse; por extensión, arte o traza con que se conduce un asunto o se emplean los medios para alcanzar un fin determinado; orientaciones o directrices que rigen la actuación de una persona o entidad en un campo determinado.

La definición extensiva, señala que es lo perteneciente a "la doctrina política; urbano, cortés con reserva, dícese de quien interviene en las cosas del gobierno y negocios del Estado" (Diccionario de la real academia españolahttp://diccionario.terra.com.pe/cgi-bin/b.pl).

Política en términos generales hace alusión al grupo de actividades calificadas como políticas es decir acciones humanas que se refieren a las cosas del Estado, de ahí, que también se le señale como doctrina o ciencia del Estado.

Si se entiende en el primer sentido, su objeto de estudio es el Estado, entendido como la institución que rige a los individuos que conforman un grupo social en un territorio especifico, sobre los cuales le corresponde legislar, extraer y distribuir los recursos. A partir de este significado surge, por un lado el poder estatal que defiende y mantiene, conquista una ideología propia como se puede apreciar en las actuales contiendas políticas.

Al entender este vocablo en el segundo sentido, el académico, es la reflexión sobre la actividad política, realizando entonces los análisis que se debaten en las aulas universitarias o que se encuentran presentes con mayor o menor profundidad en algunos programas de los medios masivos de comunicación. 
Sin embargo no debe confundirse la ciencia política con la politología que se encarga del estudio de los hechos políticos, es decir, analiza los planes gubernamentales, las diferentes formas de gobierno, la estructura gubernamental, los fines políticos.

\section{EVOLUCIÓN DEL CONCEPTO DE POLÍTICA}

En surgimiento de la política lo ubicamos en Grecia con la "polis, ciudad autónoma y soberana, cuyo cuadro institucional está caracterizado por una magistratura, por un consejo y por una asamblea de ciudadanos (politai)" (BOBBIO, 1995 p 1209)

El Protágoras de Platón considera el concepto de política como el saber concebido en función de fines prácticos...trata de definir la esencia de las virtudes cívicas fundamentales que presentan el conocimiento del bien como la esencia de toda virtud (cfr. JAEGER 1980 p 447), por lo tanto fungir como dirigente del Estado corresponde al filósofo, es una tarea de quien posee el conocimiento del bien, o sea, el fundamento del principio que erige una sociedad humana y al cual ha de dirigirse todo existir humano. Por lo que en este mismo diálogo, Sócrates se constituye como el maestro del "arte político" absorbiendo en sí, la tarea de forjar a los hombres como buenos ciudadanos (PLATÓN Protágoras 319 A) y Platón se refiere a la "techné política" como la búsqueda de una objetividad rigurosa y por lo mismo, un saber no propio de las masas, sino un saber filosófico supremo. 
Para Aristóteles el ser humano es un ser racional y un ser social, binomio que se apropia de la función comunicadora de la palabra como fundamental para expresar lo que será justo o injusto en la sociedad, lo que es valioso o no entre los hombres, lo que es dañino o bueno para el bien común, conceptos que se irán desarrollando en cada ser desde la familia hasta su inserción en la ciudad. (cfr. ARISTÓTELES, 1982). En la Política, se dirige al ser humano como el zoon politikon, el animal político es decir, el que se socializa, en este sentido, para Aristóteles, el tener una vida política y formar parte de la polis eran una misma actividad, que el hombre era político no significaba una acción mas en su vida, sino desde ella se definía, la política era una actividad inherente a la naturaleza humana. Los ciudadanos formaban parte de las asambleas pero se encontraban sujetos a una autoridad y quienes no se dedicaban a ella, se consideraban seres inferiores.

En términos romanos, la expresión 'vivir' es sinónimo de 'estar entre los hombres' lo mismo que 'morir' lo es de 'cesar de estar entre los hombres'. Esto es, el hombre en tanto hombre es necesariamente social, contexto en el que surge el concepto de Civitas, ciudades que se organizaban bajo el precepto de la ley y que jurídicamente comienza a asignar el poder en unos cuantos como la máxima autoridad: el senado y posteriormente el emperador.

En la República Romana, el ciudadano se encuentra dotado de derechos y deberes -que se han heredado hasta nuestros días- Uno de los conceptos centrales era la participación en la vida política: el derecho de sufragio "del simple derecho de ciudadanía (civita o jus civitas) dependen 
un conjunto de derechos (jura) y de deberes (munera) entre los que se incluyen las garantías jurídicas del ciudadano y las formas de participación en la vida política (la votación de las leyes, la elección de los representantes y la participación en la magistratura); a diferencia de Atenas donde se establecía por un lado el derecho a la ciudadanía (politeia) y por otro los derechos políticos (politeuma); esta diferencia primordial en Grecia, se mitiga en Roma a raíz de la ley de las XII tablas que garantiza la igualdad política entre patricios y plebeyos"(cfr. LAURENT GERBIER 2005)

En el momento en que la autoridad del clero toma fuerza, la connotación de política se vincula a la ética y será interpretada por Tomas de Aquino, desde una visión teológica partiendo de los supuestos del cristianismo (cfr. PATATABRAVA, http//.www.lapolitica.institucionespoliticas)

Para Tomas de Aquino, el Estado es un despliegue de la esencia social del hombre. A la raíz de Aristóteles de dsoon politikòn-animal políticoque incluye la familia, aldea y polis, Tomas agrega "el reino"; afirma que en la sociedad natural, el hombre nace indefenso -en comparación con otros animales-, debilidad que se soluciona a través de la razón con la que cuenta el ser humano. Pero ella, no le basta sino requiere de los demás, de manera que está destinado por su naturaleza a vivir en sociedad, lugar donde ha de realizarse. Es así, que el hombre ya no sólo buscará su propio bien, sino, el bien común, aquel que pertenece a todos (cfr.Tomas de Aquino, 1995), quedando planteado así uno de los problemas centrales de la filosofía política: la relación entre lo particular y lo universal, el individuo y la comunidad (cfr Dri Rubén 2000) 
Todo lo contrario a la posición de Maquiavelo, que separa la política de la moral, la política debía ser independiente, por que tiene sus propias leyes; autosuficiente y autárquica (se basta para explicarse a sí misma) y es -afirma Maquiavelo- causa primera, ya que genera otras esferas, como la social y la económica (cfr. IVAROLA LEONARDO, http://www.teoría -política.shtml). Así nace el concepto moderno de Estado -con una visión jerarquizada- como la principal forma de organización política. Sin embargo "históricamente: toda política supone cierta moral, y toda moral cierta política. Teóricamente: toda ética implica cierta concepción de política y de sus relaciones con la moral; y toda teoría política, supone una ética" (cfr. SÁNCHEZ VÁZQUEZ A.1980 p 17).

Hobbes afirma que el peor enemigo de un hombre es otro hombre, expresando así su concepción de ser humano: de hombre es el lobo del hombre y sostiene que al convivir con otros hombres, lo vuelve peor. Desde esta postura construye el concepto de política relacionándola con quien detenta el poder del gobierno, poder entendido como los medios para mantener una ventaja, la política todo lo previene y todo lo genera (cfr. HOBBES 1980 ).

Para Kant (1974) la política nuevamente está ligada a la moral, no puede haber disputa entre la política como aplicación de la doctrina del derecho y la moral, que es la teoría de esa doctrina; no puede haber disputa entre la práctica y la teoría. Es necesario relacionar el concepto de derecho al de política como su condición, así se concibe a un político moral -en la obra La Paz Perpetua- como quien tiene en cuenta los principios de la 
prudencia política compatibles con la moral; mas no se desarrollará así, en un moralista político, es decir, alguien que se forje una moral aplicable a un fin especial, como por ejemplo, una moral favorable a las conveniencias del Estado (cfr. KANT, 1974). En esta misma obra, nos muestra la máxima que ha de regir a los políticos -en especial a los gobernantes-: si en la constitución del Estado hay vicios que no pueden

evitarse, se deben solucionar según el derecho natural, tal y como la idea de la razón lo presenta -a los ojos- aunque para ello, tenga que vencer su egoísmo.

En el siglo XIX con la democratización del Estado, la política adquiere nuevos significados brindando al Estado la tarea de proteger los derechos del hombre. Esta relación Estado sociedad se incrementará en el siglo XX naciendo el Estado del bienestar.

En la actualidad la política se ha acercado a los seres sociales, el hombre la concibe cada vez mas, como algo que le concierne, que le va conformando en cierto sentido y por lo tanto hay que sistematizarla, hay que investigarla, hay que crearla .

\section{ACEPCIONES DE LO QUE LA POLÍTICA ES}

Desde el punto de vista teleológico, los fines que persigue la política a través de sus políticos, serán los fines de un determinado grupo social o de la clase dominante de ese grupo social. El fin en momentos de luchas sociales y civiles: es la unidad del Estado y el orden público; en tiempos que se vive la paz tanto interior como con el exterior: el bienestar y la prosperidad; en época en que un gobierno despótico oprime al pueblo: la 
conquista de los derechos civiles y políticos; en momentos de opresión por una potencia extranjera: la independencia nacional. Por lo tanto no existe el fin de la política de una vez y para siempre, sus fines se determinan de acuerdo a las metas y las circunstancias de vida que un grupo organizado se propone. Sin embargo existen condiciones necesarias para que alguna de las metas precedentes se logre: el orden público de las relaciones internas y la defensa de la integridad nacional de un Estado con otros Estados, por lo que se puede señalar éste, como fin mínimo de la política.

Algunas definiciones de política no son descriptivas señalando lo que es y en qué se concreta, sino prescriptivas al indicar lo que debe ser una buena política, al estilo de Aristóteles que define el fin de la política, no como saber vivir, sino saber vivir bien (cfr. ARISTOTELES, Política 1278b). Habría de distinguirse ¿qué es una buena y una mala vida?. Y también al estilo Aristotélico -que se encuentran en repetidos momentos de la historia- afirmar que el fin de la política es la búsqueda del bien común, y en este caso ¿cuál es aquel bien que para todos los miembros de un grupo social es común? Hay que acompañar estas definiciones con sus especificaciones, para que, no con tanta generalidad abarque todo y nada a la vez.

En cambio, al estilo maquiavélico para el político es la búsqueda del poder por el poder mismo. Esta acepción no expresa una forma específica de poder, sino más bien la forma de ejercerlo, por lo tanto, es aplicable a cualquier modo de poder (ejemplo el económico). Este tipo de poder, sería la forma mas degenerada de ejercer el poder: sin ningún 
objetivo y si este poder sin razón es el móvil de la política ¿para que serviría?

La política en tanto actividad reflexiva se extiende a toda persona como miembro que conforma a una sociedad: se participa en las actividades que determinan la forma de gobierno, en las condiciones que permiten $o$ no el ejercicio de la elección libre, en el establecimiento de la justicia... La política es un ámbito de lo más propio, tiene que ver la consideración de nuestra libertad, en el sentido de una "actitud política" o sea, el establecer acuerdos con los otros sobre aquello que nos afecta en común, se refiere a cómo se organizara la existencia del grupo social, ya que "para ser plenamente humanos se tiene que vivir entre humanos, es decir, no sólo como humanos sino también con los humanos, necesariamente en sociedad. Ya no es posible que se desentienda uno de la sociedad humana a la que pertenece, y menos hoy [en época de globalización] que ya no es del tamaño de mi barrio, ni de mi ciudad, ni de mi nación, sino que abarca el mundo entero,... hoy mas que nunca los hombres no viven aislados y solitarios sino juntos y en sociedad." (SAVATER, $2004 \mathrm{p}$ 15)

La política tiene un tiempo que afecta a mi tiempo y a tu tiempo, es decir además de reflexionar las repercusiones que tiene el tomar determinadas decisiones políticas, es ver a futuro: cómo queremos que esté estructurada la sociedad a futuro, donde vivirán "los nuestros" cuando sean adultos. Eso se construye con las políticas de hoy: sus tendencias, las instituciones, las leyes, los derechos, la administración de los bienes... 
A diferencia de la forma instintiva de 'organización social' de los animales, los seres humanos crean distintos tipos de sociedades, y aún mas, se siguen recreando ellos mismos conforme la sociedad se reconstruye. En cada orden social, no necesariamente van a responder ante él, tal y como está; sino, pueden rebelarse -no como oponentes a la sociedad- sino en tanto no estén de acuerdo con un especifico tipo de sociedad, no es un oponerse a un todo en tanto seres asóciales oantisociales-, sino ante determinados sucesos que se dan en un especifico tipo de sociedad (SAVATER, 2004 p 40).

La primitiva educación para la política comienza en la familia, al instruir al niño para que genere una conducta que le permita integrarse con cierta armonía al orden común al que ha de pertenecer, pero conforme su incorporación a la política establecida avanza, frecuentemente los conflictos también se incrementan; por que si se trata de 'nuestra nación' no siempre se coincide con las normas establecidas ni con las formas de conducir la nación; ahora que si se habla de los pueblos vecinos, estos se presentan como los otros, los adversarios.

Si se quiere ver estos desacuerdos desde otro ángulo, las discrepancias generan cambios, criticas, replanteamientos, que por lo menos, llevan a una evaluación de lo que está sucediendo; y los conflictos políticos serán mucho más complejos, entre más numerosa sea la población humana.

Cuando la política se plantea como el hacer de la polis y para la polis, puede caer en una contradicción ante su propia función del bien común, sobran ejemplos al crear males mayores ante lo que se quería resolver: como el actuar corrupto del político que sólo busca su propio beneficio o 
el abuso de la autoridad policíaca sobre aquellos ciudadanos a los que debía proteger.

El hacer política se presenta como una formación de los ciudadanos para que ejecuten una participación conciente y activa en las decisiones del gobierno que inciden en la vida social e individual de los ciudadanos; actividad que el estado lleva a cabo a través de diferentes medios masivos para forjar mejores relaciones sociales y la preservación o no de la política dominante; acción que la vida universitaria debe desarrollar.

Al educar para la política "el compromiso que han de asumir los políticos y los educadores y que deben cuidar los ciudadanos que se cumpla, es que las propias acciones políticas no se conviertan en un acto irrelevante; por el contrario, que sean un hecho cargado de significado democrático y de participación política conciente...encontrar la formula educativa que permita a los ciudadanos el ejercicio crítico y libre de su poder electoral." (GUILLEN, 2003 p 4)

Afirman los mensajes de los partidos políticos y del IFE "este 2 de julio todos los que están en capacidad están comprometidos a votar" comprometidos ¿con quién?, ¿cuando me comprometí?, un mexicano está comprometido con la gente de México a hacer uso de las propias posibilidad de voto además de evitar que otros lo hagan; quien es madre está comprometida con su familia para formar parte de los que eligen lo que consideran es mejor para vivir en el presente y en el futuro, las minorías que tienen un titulo universitario están comprometidos con todos aquéllos que queriéndolo o no, no pudieron llegar a desarrollar sus 
estudios, por que tienen la responsabilidad de decidir quien consideran que gobernará por el bien de todos.

Al decir que "cada quien es libre de votar por sus candidatos" ¿qué significa ser libre?, libre sólo aquel que con pleno conocimiento de todas las opciones elige lo que es mejor para sí y en este caso: para todos. Para elegir concientemente se necesita algo más que tener credencial de elector y asistir a las urnas. En última instancia el compromiso es como persona y por lo tanto como ente social, a colaborar para erradicar la injusticia en la que hoy viven los mexicanos y en especial los más necesitados.

Reflexionar sobre la política, sino es una obligación, por lo menos es un derecho y un deber de todo sujeto social. Es imperativo participar en la forma en la que se establece el orden, cómo se detenta el poder y la autoridad; por que, no sólo hay que añorar la paz, la estabilidad y la armonía, sino hay que hacer algo para instaurarlas, esto es, NO hay que participar de cualquier modo, los cambios sociales los realizan individuos con conciencia política que buscan resolver conflictos, hay que tomar posición para convertirse no sólo en un observador de los fenómenos políticos sino, desde la muy particular forma de estudiarlos, participar con las propias destrezas en su solución; por que no sólo se es afectado sino causa de ellos. Participar en las soluciones no nos transforma de una víctima más de la situación del país, sino en un actor reflexivo de lo que en México está sucediendo en bien de las mayorías.

La política también es un espacio, un lugar de debates, de diálogos, de consensos, de arbitrariedades...ya no le compete solo al ámbito del 
Estado, es un espacio común que se ha ampliado, se ha enriquecido y por lo tanto se ha vuelto complejo. Nuevas formas de hacer política se han elaborado, ahí las comunidades virtuales han tenido cabida; y esto se extiende no sólo a donde se hace ahora la política, sino a quienes la hacen: las decisiones políticas se discuten en las reuniones familiares, los niños conocen quienes son los candidatos a la presidencia de los diferentes partidos, los municipios pelean por sus intereses y se están constituyendo cada vez más, organismos internacionales (OEA, BM, FMI, las ONG...) que poseen mayor influencia en las decisiones políticas de un mundo que se esta globalizando.

El espacio político surge desde los griegos en el ágora que se constituye como un lugar público donde la vida política podía tomar forma: apto para la disputa, la oratoria, espacio común donde son debatidos los temas de interés general como la ética y la educación, por que el terreno político era para el griego el terreno de lo común, hacer política era participar en la vida en común, una obligación de cada ciudadano para consigo y con los demás; renunciar a hacer política era renunciar a gobernarse y por tanto, a ser libre (ROSSI 2002 p 62); pasó este espacio político entre los romanos al foro y en la sociedad actual el lugar público donde se delibera es en los medios masivos de comunicación: el televisor -presente en la mayoría de los hogares mexicanos- que se ha convertido en el campo de batalla, en una sociedad cada vez mas masificada, pero a través de él, se gana el poder. Ahora la política tiene que adaptarse a un lenguaje mediático: simplificando el comunicado personalizando la política y el predominio de los mensajes negativos de desprestigio del adversario sobre los positivos que tiene poca credibilidad. La política escándalo ha 
mostrado ser tremendamente efectiva, la telecracia ha desarrollado, mostrado sus lecciones en diferentes momentos de la historia: el nazismo y el fascismo, el uso y abuso de los medios por Perón, el joven Kennedy frente a la descuidada imagen de Nixon (cfr. SCHMID R.http://www.politica-y-ciencia), ahora hay que saber aparecer ante las cámaras, se ve tanta publicidad de los candidatos, donde el medio televisivo que podría ser altamente informativo es usado para calumniar, para la demagogia, mostrar cercanía de un discurso que no existe; por que lo que importa es la forma y no el contenido, la finalidad es ganar poder a través de la audiencia cautiva en sus propios hogares, el objetivo ganar la competencia. Este uso de la tecnología utilizando la influencia psicológica y social, aprovechándose del poder de quienes manejan los medios, a través de la manipulación y el populismo, llevan a la desinformación y debilitamiento de la democracia; mismo sentido del actuar de los sofistas: hay que seducir al público a través del uso de la palabra

Hay que entender y teorizar lo que la política es, pero a fin de cuentas ¿qué está sucediendo en estos tiempos entre nuestros políticos? calumnias, criticas y ataques de todo tipo ¿con eso están conformando la política mexicana actual?, algunos piden menos controversia y mas propuesta, si, pero ¿para qué propuestas vacías? ¿promesas vanas?, ¿les creemos? La pregunta real es ¿quién o bajo qué ideología se está realmente gobernando a México?, ¿se vota por quien se esta seguro forjará principios en bien de los mexicanos o se piensa "este es el menos peor"? A fin de cuentas en la práctica ¿qué está haciendo la política mexicana? Y ¿quiénes se están beneficiando con ella? 
Sobran ejemplos de quienes detentan hoy el poder político y han desencadenado incredulidad en la ciudadanía ante su inconsistencia al cambiar de partido fácilmente en tanto éste no responde a sus propios intereses, defendiendo con nueva bandera la misma lucha que se alternaba en la ideología contrincante.

En la actualidad la política ha surgido como un medio por el que se han entablado soluciones $\mathrm{o}$, se justifican conflictos entre las interacciones humanas tanto nacional como internacional: el desmoronamiento de la URSS, la unión Europea, la guerra de Irak, el movimiento de los inmigrantes en los Estados Unidos; ¿se puede a través de la política entablar cambios sustanciales en la realidad mexicana? ¿será con las próximas elecciones que las políticas propuestas levanten a nuestra sociedad de la forma indignante de vida, de la corrupción, de la desconfianza en los dirigentes, de la inseguridad...? Para ello se necesita -en primer lugar- un conocimiento claro de las exigencias de la población para brindar el beneficio al mayor número posible de personas y -en segunda instancia- auténticos seres humanos que actúen con principios firmes, es decir, los políticos no sólo han de conocer su objeto de estudio que es la realidad social, sino las valoraciones de esta realidad; ya que el pensar y hacer de cada una de sus decisiones, afectan a su pueblo, no pueden eludir la norma moral (al estilo Maquiavélico) que rige sus actos, por que el tratar de hacerlo ya evidencian un tipo de moral. El actuar con valores humanos no le quita objetividad al científico que se dedica hoy a hacer política. 
Es así que la política envuelve actividades esencialmente humanas que competen a todos en tanto seres que conforman una sociedad: son acciones humanas referentes al Estado, son fines de un grupo social, es poder en una autoridad, es una actividad inherente a la naturaleza humana, es lo común a un pueblo, es orden público, es dialogo, es un arma de poder, es controversia, es una propuesta de solución a los conflictos sociales, es búsqueda del bien común..., todo ello y en lo que en cada momento se convierte, no depende de ella misma, sino de quienes la detentan. En política nada está escrito, cada día se construye a sí misma con el ser y el hacer de los hombres.

Referencias

Aristóteles (1982) Política, México: Porrua, S.A.

Bobbio N., Matteucci N. y Pasquino G, (1995) Diccionario de política, México: Siglo XXI editores

Diccionario de la real academia española, http://diccionario.terra.com.pe/cgi-bin/b.pl)

Dri Rubén (2000) Teología política de santo tomas En la filosofía política clásica. De la antigüedad al renacimiento. Argentina: Colec CLASCO_EUDEBA

Ferrater Mora, J. (1980) Diccionario de Filosofía, Madrid: Alianza diccionarios

Gerbier Laurent, "Hablar al pueblo: el uso de la contio desde la antigüedad al renacimiento", Erythesis, 1 mayo 2005. 
Gómez Guido, S. (2001) Diccionario etimológico de la lengua española, México: Fondo de cultura económica

Guillén Niemeyer B. (2003) Política para educar y educar para la política, México: en Paedagogium

Hobbes Thomas (1980) Leviatán Madrid: Editora Nacional

Ivarola Leonardo, http://www.teoría -política.shtml

Jaeger Warner (1980) Paideia, los ideales de la cultura griega, México: Fondo de cultura económica

Kant (1974) La Paz Perpetua Madrid: Espasa Calpe, colec. Austral

Larousse (2001) Diccionario de sinónimos y antónimos e ideas afines, México: Larousse.

Patatabrava, http//.www.lapolitica.institucionespoliticas

Platón (1981) "Protagoras" en Obras Completas, Madrid: Aguilar

Rossi M. y Armadeo J. (2002) "Platón y Aristóteles: dos miradas sugestivas en torno a la política" en Teoría y Filosofía Política, Buenos Aires :Consejo Latinoamericano de Ciencias Sociales

Sánchez Vázquez A. (1980) "Notas sobre la relación entre moral y política" en Thesis. Nueva revista de filosofía y letras. México: UNAM

Savater Fernando (2004) Política para Amador, Barcelona: Ariel

Schmid R. http://www.politica-y-ciencia 